\title{
The effect of ER4043 and ER5356 filler metal on welded Al 7075 by metal inert gas welding
}

\author{
M. N. M. Salleh, M. Ishak, L. H. Shah \& S. R. A. Idris \\ Faculty of Mechanical Engineering, \\ Universiti Malaysia Pahang, Malaysia
}

\begin{abstract}
Al 7075 is widely used in the automobile and aviation industry due to its light weight, strength, and good durability. Fusion welding such as metal inert gas (MIG) is commonly used in joining aluminium alloys. It was used because of its low cost and is generally used by welders. However, defects usually occurred using fusion welding because of improper welding parameters and the types of filler metal used. The purpose of the study is to investigate the effect of filler metal and welding parameters on the mechanical properties of welded Al 7075. The welding parameters used are current, voltage, welding speed, and Argon (Ar) as shielding gas. Two different types of filler metal, namely, Electrode Rod (ER) 4043 and ER5356 have been used. From microstructure analysis, the fusion zone (FZ) of a sample welded with ER4043 has a smaller grain size than that of one welded with ER5356. Both fillers produce equiaxed dendritic grain at FZ. Both samples welded with ER4043 and ER5356 have a lower hardness value than the heat affected zone (HAZ) and base metal (BM) due to the differences in their main elements where ER4043 is Al-Si and ER5356 is Al-Mg. The weld efficiency of a sample welded using ER5356 was 61\% which was higher compared with a sample welded using ER4043, which is $43 \%$ and both samples were brittle fractured. The sample welded with ER5356 was fractured at HAZ due to porosity while the sample welded with ER4043 fractured at FZ due to the oxide inclusion at FZ.
\end{abstract}

Keywords: Al 7075, ER4043, ER5356, MIG, mechanical properties, microstructure analysis. 


\section{Introduction}

Aluminium alloys 7075 (Al-Zn-Mg) have been utilized throughout aircraft and aerospace structure. This metal is heat treatable and the strongest and the most durable of aluminium alloys [1]. Al 7075 was largely used in the automobile and aerospace industry $[2,3]$. In addition, connecting rods, axle shafts, rims, as metals in bumpers and door beams in car bodies are made from Al 7075 [4]. It has been used largely for the body of aircraft and for the fuel tank in spacecraft. This is due to its characteristics of being lightweight, strong and very durable and it also has good machinability [5]. TIG and MIG were mostly used in the joining process of aluminium alloys [6-10], but MIG welding was preferable since it is widely used for welding aluminium and produces a good weld quality [7]. Filler metal plays an important role in fusion welding since the selection of filler metal type can affect the welded joint. 7N01 alloys of 7000 series aluminium alloys with other aluminium alloys such as the 5000 and 6000 series where they are applicable as structural material in the automobile sector had been welded with filler wire ER5356 using the DCEP-MIG welding method [4, 7, 11]. This means that the common filler wire used for welding aluminium alloys is ER5356 (Al-Mg). The joining method used for this study is Direct Current Electrode Positive (DCEP) Pulse Metal Inert Gas (MIG). This research is to study the mechanical and microstructure of welded Al 7075 when welded with another type of filler metal which is ER4043 from the 4000 series of aluminium alloys (Al-Si). Thus, the mechanical properties and microstructure of a welded sample with ER4043 will be compared with ER5356. The welded Al 7075 aluminium alloys joint will undergo mechanical testing, such as the Vickers hardness test and tensile test as well as microstructure and EDX analysis in order to observe the microstructure after welding by ER4043 and ER5356. This investigation is also to distinguish the fracture behavior when welded with both fillers.

\section{Experimental procedures}

In this study, Al 7075 with $2 \mathrm{~mm}$ thickness was used and the chemical composition of Al 7075 as well as the filler wires is shown in Table 1. Al 7075 presents $\mathrm{Zn}$ and $\mathrm{Mg}$ as the major alloying element with $5.58 \%$ and $2.28 \%$, respectively. ER4043 shows $\mathrm{Si}$ is the alloying element with $6.0 \%$ and ER5356 shows $\mathrm{Mg}$ is the alloying element for 5.5\%. Al 7075 were cut in dimensions of $150 \times 150 \times 2 \mathrm{~mm}$. An ASTM E8 tensile sample was produced from welded specimens using a CNC milling machine. The illustration for the tensile sample from the welded specimen is shown in Figure 1. The results of the tensile test were recorded in order to compare the strength between the parent metal Al 7075 with that welded by both fillers. Then, the welded sample was hot mounted for microstructure observation and Vickers' hardness testing. An optical microscope was used to observe the microstructure of a welded sample cross section. Based on Box-Behnken, 14 samples are needed for each experiment and due to the differences in chemical composition of fillers, the range of parameters for 
current, voltage and welding speed are different. The listing of experimental parameters is shown in Table 2 .

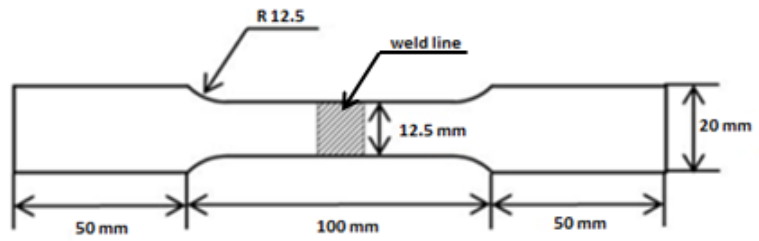

Figure 1: ASTM E8 tensile sample.

Table 1: Chemical composition of Al 7075 aluminium alloys and filler wire.

\begin{tabular}{|c|c|c|c|}
\hline \multirow{2}{*}{ Element } & \multicolumn{3}{|c|}{ Composition (wt\%) } \\
\cline { 2 - 4 } & $\mathrm{Al} 7075$ & ER4043 & ER5356 \\
\hline $\mathrm{Mg}$ & 2.28 & 0.05 & 5.50 \\
\hline $\mathrm{Zn}$ & 5.58 & 0.10 & 1.00 \\
\hline $\mathrm{Si}$ & 0.07 & 6.00 & 0.25 \\
\hline $\mathrm{Fe}$ & 0.27 & 0.80 & 0.40 \\
\hline $\mathrm{Cu}$ & 1.60 & - & - \\
\hline $\mathrm{Mn}$ & 0.02 & - & - \\
\hline $\mathrm{Al}$ & Bal. & Bal. & Bal. \\
\hline
\end{tabular}

Table 2: Welding conditions.

\begin{tabular}{|l|c|}
\hline Working parameter & Description \\
\hline Process & DCEP-Pulse MIG welding \\
\hline Shielding gas & $25 \mathrm{~L} / \mathrm{min}-\mathrm{Ar}$ \\
\hline Workpiece dimension & Al 7075-150 $\times 150 \times 2 \mathrm{~mm}$ \\
\hline Filler metal & ER4043, ER5356(1.0mm-diam) \\
\hline Current & $105-115 \mathrm{~A}(4043)$ \\
& $100-110 \mathrm{~A}(5356)$ \\
\hline Voltage & $17.5-18 \mathrm{~V}(4043)$ \\
& $16.0-20 \mathrm{~V}(5356)$ \\
\hline Welding speed & $3-5 \mathrm{~mm} / \mathrm{s}(4043)$ \\
& $2-4 \mathrm{~mm} / \mathrm{s}(5356)$ \\
\hline
\end{tabular}




\section{Result and discussion}

\subsection{Microstructure analysis}

Figure 2 shows the microstructure of a welded Al 7075 cross section at three different locations using filler rod ER5356 and ER4043. For the base metal (BM) microstructure, it was found that the spheroidal particles which were the dark precipitates represented the $\mathrm{MgZn}$ elements and the light grey particles represented the $\mathrm{FeAl}_{3}$ [12]. The grains elongated horizontally along one direction only. It was found that the equiaxed dendritic network grain presented at FZ of both samples welded by ER4043 and ER5356. The grain size at FZ was different for both samples. The average grain size of FZ, HAZ, and BM is presented in Table 3. The grain size in FZ for ER5356 was larger than the grain size for ER4043 with $99.50 \mu \mathrm{m}$ and $92.58 \mu \mathrm{m}$, respectively. The microstructure at the partially melted zone (PMZ) which was the transition region between the FZ and HAZ was a typical coarse columnar grain [13]. This was due to the zone having deteriorated with the heat of welding during the melting and solidification process [7]. There was approximately similar average grain size in HAZ and BM for both samples.

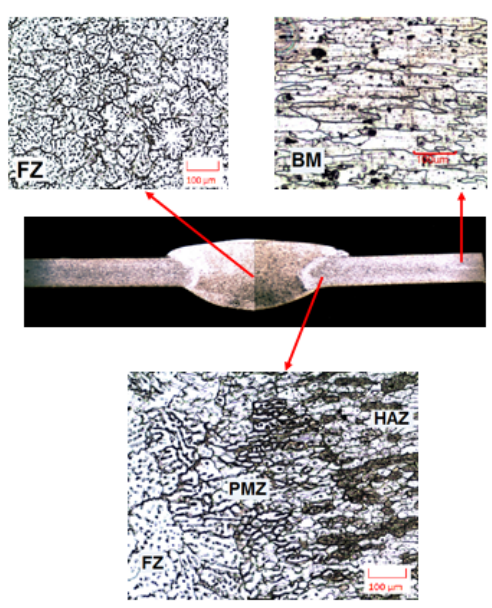

(a)

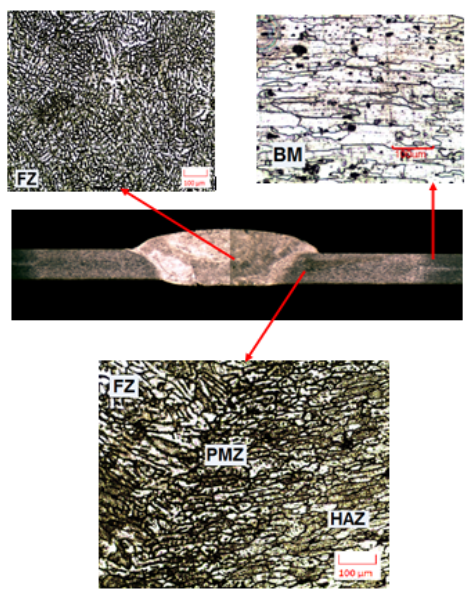

(b)

Figure 2: Microstructure image of welded cross section (a) Al 7075 with ER5356 and (b) Al 7075 with ER4043.

Table 3: $\quad$ Average grain size of microstructure.

\begin{tabular}{|l|c|c|}
\hline \multirow{2}{*}{ Region } & \multicolumn{2}{|c|}{ Average grain size $(\mu \mathrm{m})$} \\
\cline { 2 - 3 } & ER5356 & ER4043 \\
\hline Fusion zone (FZ) & 99.50 & 32.58 \\
\hline Heat affected zone (HAZ) & 95.28 & 95.34 \\
\hline Base metal (BM) & 131.24 & 131.20 \\
\hline
\end{tabular}




\subsection{EDX analysis}

The energy dispersive X-ray (EDX) with spot analysis on FZ, HAZ and BM of the welded Al 7075 using fillers ER4043 and ER5356 has been conducted. The results for the base metal are tabulated in Table 4. Figure 3 shows the spot EDX analysis of the Al 7075 base metal. It was found that the atomic percentage of $\mathrm{Al}$ and $\mathrm{Cu}$ presents much higher than other elements (as shown in Table 4). It shows that the silverish spot was due to the $\mathrm{Al}-\mathrm{Cu}$ compound which presented in $\mathrm{Al}$ 7075 .

Table 4: Element concentration for Al 7075 base metal.

\begin{tabular}{|c|c|c|c|c|c|c|}
\hline \multirow{2}{*}{ Point } & \multicolumn{6}{|c|}{ Elements concentration (\%) } \\
\cline { 2 - 7 } & $\mathrm{Al}$ & $\mathrm{Zn}$ & $\mathrm{Mg}$ & $\mathrm{Cu}$ & $\mathrm{Fe}$ & $\mathrm{Si}$ \\
\hline 1 & 41.1 & 1.3 & 1.3 & 33.0 & 8.0 & 2.0 \\
\hline 2 & 90.9 & 4.2 & 3.5 & - & - & 1.4 \\
\hline 3 & 90.3 & 4.0 & 3.4 & - & - & 1.6 \\
\hline
\end{tabular}

At points 2 and 3, which are the grey parts showing a higher percentage of $\mathrm{Zn}$ element of $4.0 \%-4.2 \%$ and $\mathrm{Mg}$ element with $3.4 \%-3.5 \%$ (as shown in Table 4 ). It was found that points 2 and 3 were from the Al-Zn-Mg compound. From this result, it was proven that the sample used in this experiment was Al 7075, which is the Al-Zn-Mg-Cu aluminium alloy. The results from EDX were approximately the same as the results from the spectrometer for the BM (as shown in Table 1). There was no IMC interaction in $\mathrm{BM}$ of $\mathrm{Al} 7075$ as the percentage of element found was normally present in this metal.

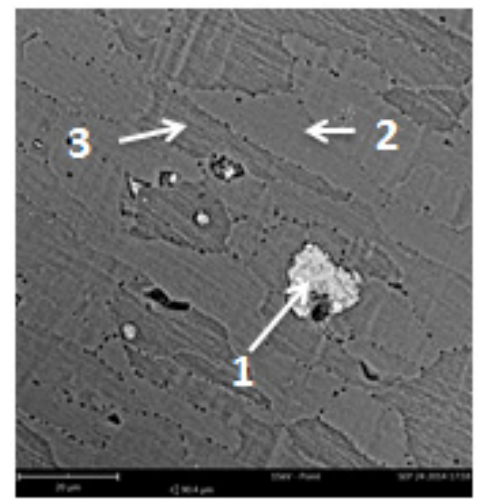

Figure 3: EDX spot analysis of Al 7075 base metal.

Table 5 shows the result of element concentration percentage and Figure 4 shows the EDX image at FZ and HAZ for a sample welded with filler ER5356.

In Figure 4(a), point 1 shows the silverish part in FZ where the atomic percentage of element $\mathrm{Cu}$ is $47.1 \%$ (highest), $\mathrm{Al}$ is 45.9 (2nd highest), and $\mathrm{Mg}$ is 
$2.8 \%$ (3rd highest) (as shown in Table 5). It was found that $\mathrm{Cu}_{\mathrm{m}} \mathrm{Al}_{\mathrm{n}}$ compound presented relatively high at point 1 . Point 2 shows the black spot which only has an atomic percentage of elements of $\mathrm{Al}$ with $95.1 \%$ (highest) and $\mathrm{Mg}$ with $4.9 \%$. The black spot was proven to be the Al-Mg element. Point 3 shows the light grey spot which also only has $\mathrm{Al}$ and $\mathrm{Mg}$ elements. It was found that the particles of $\mathrm{Al}-\mathrm{Mg}$ elements has the majority area from Figure 5(a) and a little amount of $\mathrm{Cu}_{\mathrm{m}} \mathrm{Al}_{\mathrm{n}}$ compound present in the $\mathrm{FZ}$. It was proven that some compound of $\mathrm{Cu}_{\mathrm{m}} \mathrm{Al}_{\mathrm{n}}$ presented in $\mathrm{FZ}$ due to the IMC interaction because $\mathrm{Cu}$ element was originally from the BM element since it is not present as the alloying element in ER5356. In Figure 4(b), point 4 shows a silverish spot which has an atomic percentage of $\mathrm{Al}$ at $43.3 \%$ (highest); $\mathrm{Cu}$ is $19.3 \%$ (2nd highest), Fe is $9.9 \%$ (3rd highest), and $\mathrm{Zn}$ is $4.4 \%$ (4th highest). It was found that point 4 consists of $\mathrm{Fe}_{\mathrm{m}} \mathrm{Al}_{\mathrm{n}}$ compound and the $\mathrm{Cu}$ element was normally found as the alloying element for $\mathrm{Al}$ 7075. Point 5 shows a dark grey part in HAZ which has Al with 95.0\% (highest), $\mathrm{Zn}$ with 3.5\% (2nd highest), and $\mathrm{Mg}$ with $1.5 \%$ (3rd highest). It was evident that the element presented in point 5 was $\mathrm{Al}-\mathrm{Zn}-\mathrm{Mg}$ which is the same element as the parent metal. Point 6 shows the black spot which has higher $\mathrm{Mg}$ concentration at $2.8 \%$ after $97.2 \%$ of $\mathrm{Al}$ (highest). From the EDX analysis

Table 5: $\quad$ Element concentration for welded Al 7075 using filler ER5356.

\begin{tabular}{|c|c|c|c|c|c|c|}
\hline \multirow{2}{*}{ Point } & \multicolumn{7}{|c|}{ Elements concentration (\%) } \\
\cline { 2 - 7 } & $\mathrm{Al}$ & $\mathrm{Zn}$ & $\mathrm{Mg}$ & $\mathrm{Cu}$ & $\mathrm{Fe}$ & $\mathrm{Si}$ \\
\hline 1 & 45.9 & - & 2.8 & 47.1 & - & - \\
\hline 2 & 95.1 & - & 4.9 & - & - & - \\
\hline 3 & 95.6 & - & 4.4 & - & - & - \\
\hline 4 & 43.3 & 4.4 & 1.8 & 19.3 & 9.9 & 2.4 \\
\hline 5 & 95.0 & 3.5 & 1.5 & - & - & - \\
\hline 6 & 97.2 & - & 2.8 & - & - & - \\
\hline
\end{tabular}

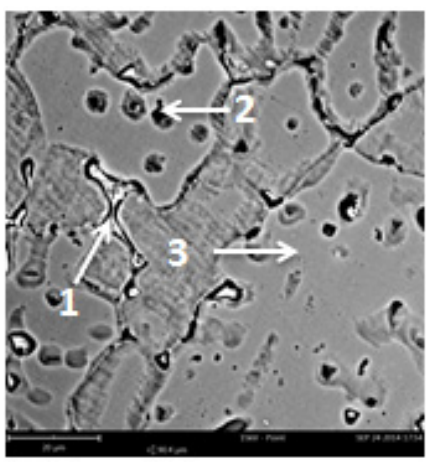

(a)

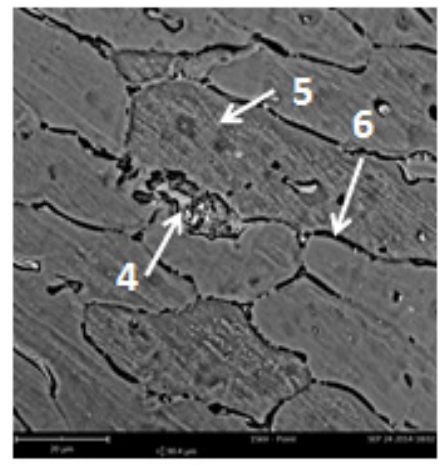

(b)

Figure 4: EDX spot analysis sample with ER5356: (a) fusion zone and (b) heat affected zone. 
for the sample welded with filler ER5356, the element found in FZ was Al-Mg which came from the ER5356 element. At HAZ, the grey part was the majority area and it is from $\mathrm{Al}-\mathrm{Zn}-\mathrm{Mg}$ which is the base metal element with a small presence of $\mathrm{Fe}_{\mathrm{m}} \mathrm{Al}_{\mathrm{n}}$ compound due to the presence of the Fe element in both the filler rod and parent metal which was $0.4 \%$ and $0.27 \%$, respectively (as shown in Table 1).

Table 6 shows the result of element concentration percentage and Figure 5 presents the EDX image at FZ and HAZ for a sample welded with filler ER4043. In Figure 5(a), point 1 shows the silverish spot in the FZ with the atomic percentage of element $\mathrm{Al}$ being 56.6\% (highest); $\mathrm{Si}$ is $23.1 \%$ (2nd highest), and $\mathrm{Mg}$ is $10.9 \%$ (3rd highest). It was shown that at point 1, the Al-Si element was from ER4043 which is from Al-Si alloy group. It was relatively high for the atomic percentage of $\mathrm{Mg}$ element in $\mathrm{FZ}$ due to the IMC interaction that occurs during the solidifying process and it produced an $\mathrm{Al}_{\mathrm{m}} \mathrm{Mg}_{\mathrm{n}}$ compound. Point 2 shows the dark elongated grain spot which contains an atomic percentage of $\mathrm{Al}$ with 39.6\% (highest), Si with 20.4\% (2nd highest), and $\mathrm{Cu}$ with $6.5 \%$ (3rd highest). It was proven that point 2 also consists of an Al-Si element as the major elements and $\mathrm{Cu}$ presents as the IMCs occur after the welding process with $\mathrm{Al}_{\mathrm{m}} \mathrm{Cu}_{\mathrm{n}}$ compound. Point 3 represents the light grey area which was the majority area in $\mathrm{FZ}$ where it has the element concentration of $\mathrm{Al}$ with $94.5 \%$ (highest), Si with $2.4 \%$ (2nd highest), and $\mathrm{Mg}$ and $\mathrm{Zn}$ represents approximately the same concentration percentages with $1.7 \%$ and $1.5 \%$, respectively. It was found that in this region, the elements from a parent metal such as $\mathrm{Mg}$ and $\mathrm{Zn}$ were solidified together with the elements presented in the weld metal produced IMCs. It was proven that in FZ for a specimen welded with ER4043, the majority element was $\mathrm{Al}-\mathrm{Si}$ which is the same alloying element of this filler where a small amount of $\mathrm{Al}_{\mathrm{m}} \mathrm{Cu}_{\mathrm{n}}$ and $\mathrm{Al}_{\mathrm{m}} \mathrm{Mg}_{\mathrm{n}} \mathrm{IMCs}$ presented.

Table 6: Element concentration for welded Al 7075 using filler ER4043.

\begin{tabular}{|c|c|c|c|c|c|c|}
\hline \multirow{2}{*}{ Point } & \multicolumn{7}{|c|}{ Elements concentration (\%) } \\
\cline { 2 - 7 } & $\mathrm{Al}$ & $\mathrm{Zn}$ & $\mathrm{Mg}$ & $\mathrm{Cu}$ & $\mathrm{Fe}$ & $\mathrm{Si}$ \\
\hline 1 & 56.6 & 1.2 & 10.9 & 5.0 & 3.2 & 23.1 \\
\hline 2 & 39.6 & 1.6 & 2.1 & 6.5 & - & 20.4 \\
\hline 3 & 94.5 & 1.5 & 1.7 & - & - & 2.4 \\
\hline 4 & 25.4 & 6.7 & 2.1 & 40.7 & 2.7 & 3.9 \\
\hline 5 & 96.2 & - & 3.8 & - & - & - \\
\hline 6 & 81.0 & 9.5 & 3.5 & 6.0 & - & - \\
\hline
\end{tabular}

From Figure 5(b), point 4 shows the silverish spot which consists of a percentage of the element $\mathrm{Cu}$ of $40.7 \%$ (highest); $\mathrm{Al}$ with $25.4 \%$ (2nd highest), and $\mathrm{Zn}$ with $6.7 \%$ (3rd highest). Therefore, point 4 has the element $\mathrm{Cu}$ as the majority element for the silverish spot where it was possibly from the Al 7075 parent metal. Point 5 shows the light grey parts from the HAZ where it has the atomic percentage of $\mathrm{Al}$ with $96.2 \%$ (highest) followed by $\mathrm{Mg}$ with $3.8 \%$. It was proven that the light grey parts were from Al-Mg alloying elements from the 


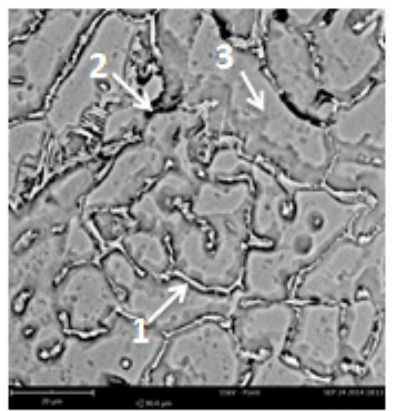

(a)

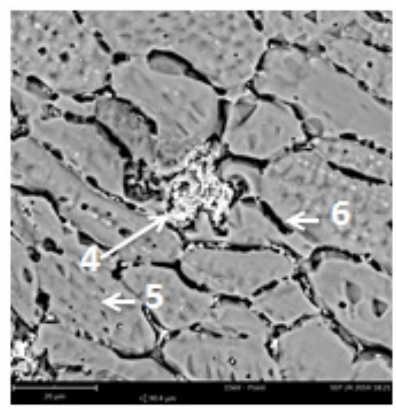

(b)

Figure 5: EDX spot analysis sample with ER4043: (a) fusion zone and (b) heat affected zone.

parent metal. Point 6 shows the black elongated spot in the HAZ microstructure. It was found that the atomic percentage of $\mathrm{Al}$ was the highest with $81.0 \%$ along with a small percentage of its alloying element such as $\mathrm{Zn}, \mathrm{Mg}$, and $\mathrm{Cu}$ (as shown in Table 6). It was proven that the HAZ of the sample welded using filler ER4043 has a very small amount of Si percentage. Therefore, the IMCs' interaction with the Al-Si compound does not occur for this sample due to the small amount of Si presented in HAZ. From the EDX results, the FZ region for the sample welded with filler ER5356 has the element of Al-Mg due to the larger area of greyish part. For its HAZ, it was found that it has an Al-Zn-Mg element the same as the Al 7075 base metal element. For the sample welded with filler ER4043, Si presents higher than other elements in FZ due to the major alloying element for ER4043 being $\mathrm{Si}$. The HAZ region from this sample shows the element of Al-Zn-Mg being same as the Al 7075 base metal with some percentage of Si elements (as observed from the grey area in Figure 6).

\subsection{Vicker's hardness}

Figure 6 shows the macrostructure images of samples with the UTS for both fillers. The average value of hardness test was presented in Table 7.

In Figure 6, it was found that the hardness value for the FZ region was lower than for the HAZ and BM. The average hardness values of the FZ region for both experiments were approximately similar, namely, $82.3 \mathrm{HV}$ and $80.9 \mathrm{HV}$ for the experiment with fillers ER5356 and ER4043, respectively. The average

Table 7: Average Vicker's hardness value.

\begin{tabular}{|l|c|c|}
\hline Position & \multicolumn{2}{|c|}{ Average hardness value (HV) } \\
\hline Filler & ER5356 & ER4043 \\
\hline Fusion zone (FZ) & 82.30 & 80.90 \\
\hline Heat affected zone (HAZ) & 120.5 & 112.7 \\
\hline Base metal (BM) & 109.7 & 103.6 \\
\hline
\end{tabular}




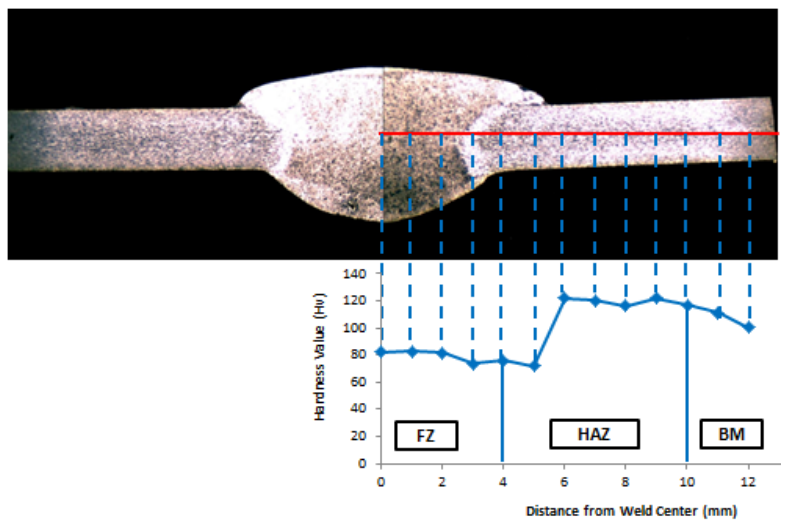

(a)

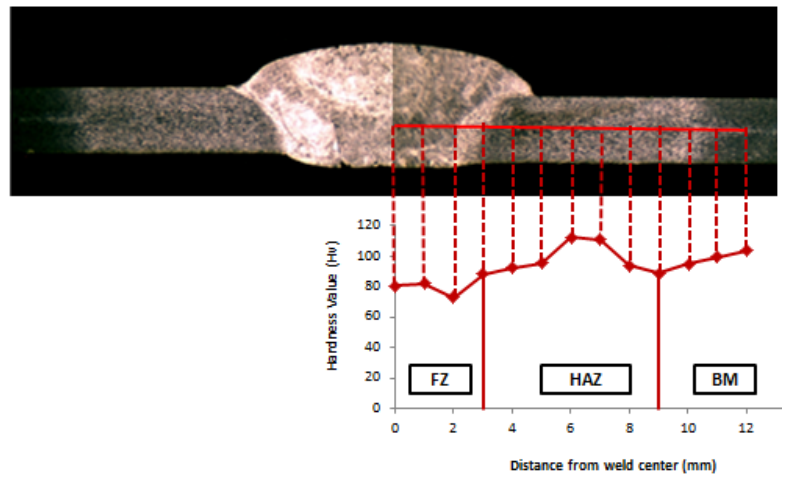

(b)

Figure 6: Macrostructure image for Vickers' hardness test: (a) welded with ER5356 and (b) welded with ER4043.

hardness value at position HAZ was the highest for both welded samples with 120.5 HV and 112.7 HV for ER5356 and ER4043, respectively. The hardness value at HAZ was higher than the other region because the microstructure at HAZ was different due to the heat from the welding process that changes the microstructure of BM.

\subsection{Tensile strength}

The tensile test result was recorded and a graph of UTS is presented in Figure 7 for welded Al 7075. Welded specimen 7 from both experiments using fillers ER4043 and ER5356 recorded the highest UTS of 359.35 Mpa and 255.03 Mpa, respectively were compared with the UTS of the parent metal, which is 590.41 Mpa (as shown in Figure 7(a)). It was clearly observed from Figure 2 that at HAZ, the coarser columnar grain microstructure was produced starting from 
the PMZ and the grain size at HAZ was also smaller than the grain size at BM for both samples. Although the grain size of FZ from the ER4043 experiment was smaller than that of ER5356, the hardness value was higher for FZ from the ER5356 experiment. It was due to the different groups of element of filler rod where for the 4xxx series from the Al-Si group, it has a $\mathrm{Si}$ element as its major alloying element which has a lower hardness than the 5xxx series from the Al$\mathrm{Mg}$ group, which has the $\mathrm{Mg}$ element as its major alloying element. The 7xxx series from the Al-Mg-Zn group has the higher hardness value based on the results obtained from this testing. It was proven that the hardness value at HAZ and $\mathrm{BM}$ was higher than the FZ zone for both samples.

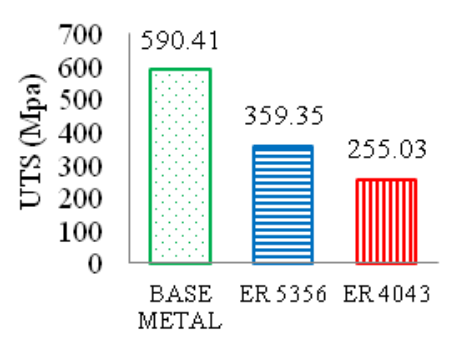

Al 7075 Specimen

(a)

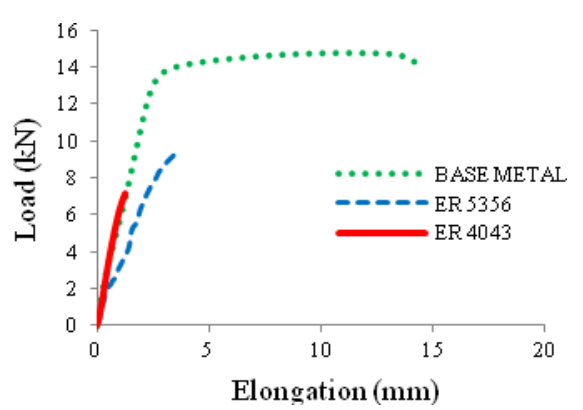

(b)

Figure 7: Ultimate tensile strength of Al 7075: (a) bar graph of UTS and (b) graph of load vs. elongation.

The weld efficiency of ER4043 and ER5356 was 43\% and 61\%, respectively showing that a sample welded with filler ER5356 has higher efficiency compared with a sample welded with filler ER4043. This is because filler ER5356 has $\mathrm{Mg}$ as its major alloying element which is stronger than $\mathrm{Si}$, which is the major alloying element for filler ER4043. It was found that the UTS of a welded sample using ER4043 dropped by 56\% from the UTS of the base metal while the welded sample using ER5356 dropped by 39\%. The sample welded using filler ER5356 proved to be a better filler metal to weld Al 7075 compared with filler ER4043. The tensile test parameter was fixed - the speed at 0.083 $\mathrm{mm} / \mathrm{s}$ and load at $50 \mathrm{kN}-$ and it did not affect the UTS.

Figure 7(b) shows the load versus elongation plot for the tested sample. This graph shows the fracture behavior of the tested sample. Al 7075 base metal shows the different plot since it had plastic deformation before it fractured. This explained that $\mathrm{Al} 7075$ has a ductile behavior due to the plastic deformation occurring before the fracture occurs. For a specimen welded with filler rod ER5356 and ER4043, there is no plastic deformation because of sudden fracturing occurring when certain loads were applied. It was found that after welding with ER4043 and ER5356, brittle behavior occurred. 


\subsection{Fracture analysis}

The welded sample with ER5356 was fractured at the HAZ region. For ER4043, it was fractured at the FZ region. Figure 8 shows the SEM image of the fracture surfaces for both samples. It was found that both samples welded with ER4043 and ER5356 fractured at these regions due to the imperfection after the welding processes and it shows brittle fracture behavior.

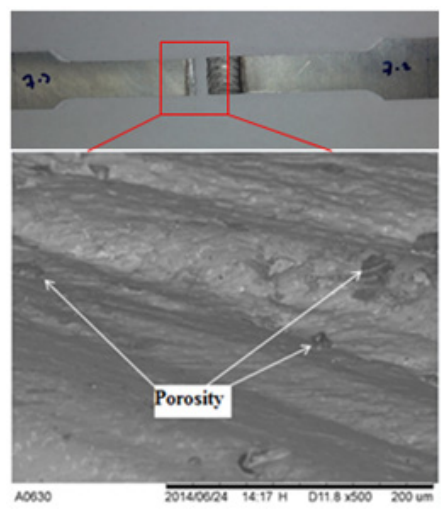

(a)

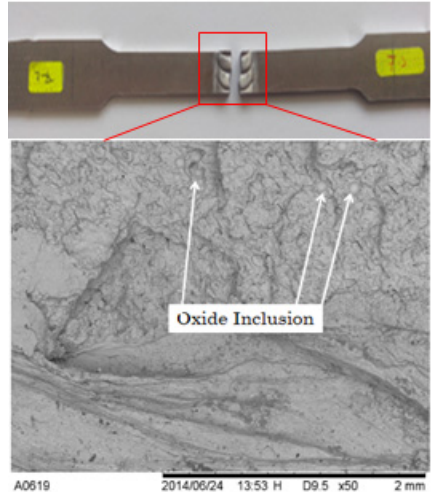

(b)

Figure 8: SEM image of fracture surface: (a) fracture surface of sample welded by ER5356 and (b) fracture surface of sample welded by ER4043.

Figure 8(a) shows that porosity presented in the HAZ and contributes to the fracture occurring at the HAZ region for a sample welded with filler ER5356. Meanwhile, the presence of oxide inclusion at the FZ due to the presence of oxide contributes to the welded samples of ER4043 being fractured at the FZ region (as shown in Figure 8(b)). It was found that a sample welded with ER4043 has a lower strength as it fractured at the FZ region due to the presence of oxide inclusion compared with a sample welded with ER5356 which fractured at the HAZ due to porosity defects.

\section{Conclusion}

The following points are concluded from this experiment for the effect of fillers ER4043 and ER5356 on the welded A1 7075:

1. It was observed that the microstructure sample in FZ was different for both fillers in terms of their grain size.

2. Smaller amounts of IMC compound such as $\mathrm{Al}_{\mathrm{m}} \mathrm{Cu}_{\mathrm{n}}$ were produced at the $\mathrm{FZ}$ for both fillers.

3. The hardness at the FZ region is lower compared with HAZ and BM for both fillers, while the weld efficiency when welded by ER5356 was higher than when welded by ER4043 when mechanical testing was investigated. 
4. Fracture at HAZ and FZ occurs for a welded sample by ER5356 and ER4043, respectively. This is due to oxide inclusion for ER5356 and porosity for ER4043.

\section{References}

[1] T. Fakuda, "Weldability of 7000 series aluminium alloy materials," Welding International, vol. 26, pp. 256-269, 2012.

[2] J. F. Tu and A. G. Paleocrassas, "Fatigue crack fusion in thin-sheet aluminum alloys AA7075-T6 using low-speed fiber laser welding," Journal of Materials Processing Technology, vol. 211, pp. 95-102, 2011.

[3] S. Stano, T. Pfeifer, and M. Różański, "Modern technologies of welding aluminium and its alloys", Welding International, vol. 28, pp. 91-99, 2014.

[4] M. Ema, "Tensile strength of MIG-welded 7000 series aluminium alloy extrusions," Welding International, vol. 22, pp. 661-668, 2008.

[5] K. G. Budinski and M. K. Budinski, Engineering Materials, Properties and Selection, 8th ed.: Prentice-Hall, 2005.

[6] J. M. Fortain and S. Gadrey, "How to select a suitable shielding gas to improve the performance of MIG and TIG welding of aluminium alloys," Welding International, vol. 27, pp. 936-947, 2013.

[7] S. M., M. N., A. D., and R. K. S., "Investigation of microstructure and mechanical properties of gtaw and gmaw joints of aa7075 aluminum alloy" International Journal on Design and Manufacturing Technologies, vol. 3, pp. 56-62, 2009.

[8] F. Miyasaka, T. Okuda, and T. Ohji, "Effect of current wave-form on AC TIG welding of aluminium alloys," Welding International, vol. 19, pp. 370-374, 2005.

[9] M. H. M. Temmar, T. Sahraoui, "Effect of post-weld aging treatment on mechanical properties of Tungsten Inert Gas welded low thickness 7075 aluminium alloy joints.," Material and Design, vol. 32, pp. 3532-3536, 2011.

[10] V. R. V. Balasubramanian, G. Madhusudhan Reddy “ Influences of pulsed current welding and post weld aging treatment on fatigue crack growth behaviour of AA7075 aluminium alloy joints.," International Journal of Fatigue, vol. 30, pp. 405-416, 2008.

[11] M. Ema, "Tensile strength of MIG-welded aluminium alloys for structures," Welding International, vol. 22, pp. 199-205, 2008.

[12] P. Z. Zhao and T. Tsuchida, "Effect of fabrication conditions and $\mathrm{Cr}, \mathrm{Zr}$ contents on the grain structure of 7075 and 6061 aluminum alloys," Materials Science and Engineering, vol. A 499, pp. 78-82, 2009.

[13] X. Cao, W. Wallace, J. P. Immarigeon, and C. Poon, "Research and Progress in Laser Welding of Wrought Aluminum Alloys. II. Metallurgical Microstructures, Defects, and Mechanical Properties," Materials and Manufacturing Processes, vol. 18, pp. 23-49, 2003. 